\title{
A Perspectiva CTS e o Ensino de Ciências entre Acadêmicos de Engenharia Ambiental: manifestações discursivas
}

\author{
The STS Perspective and the Teaching of Science between Academics \\ of Environmental Engineering: discursive manifestations
}

\section{Fernanda Peres Ramos1, Marcos Cesar Danhoni Neves2, Michel Corci Batista3, Mariana Pereira Souza4}

1 Pós-doutora em Educação para a Ciência e Matemática, Universidade Tecnológica Federal do Paraná, Campo Mourão, Paraná, Brasil - fernandaperes29@gmal.com/ https://orcid.org/0000-0002-4435-2513

2 Doutor em Educação, Universidade Estadual de Maringá, Maringá, Paraná, Brasil macedane@yahoo.com.br/https://orcid.org/0000-0001-5209-4158

3 Doutor em Educação para a Ciência e Matemática, Universidade Tecnológica Federal do Paraná, Campo Mourão, Paraná, Brasil - michel@utfpr.edu.br /https://orcid.org/0000-0001-7328-2721

4 Graduanda em Engenharia Ambiental, Universidade Tecnológica Federal do Paraná, Campo Mourão, Paraná, Brasil marianasouza111.ms@gmail.com /https://orcid.org/0000-0002-4435-2513

Recebido em 29/07/2018. Publicado em Agosto/2019

Palavras-chave:

Ciência, Tecnologia e

Sociedade (CTS);

Análise do Discurso

(AD); Engenharia

Ambiental.

Keywords:

Science, Technology and Society (STS); Discourse Analysis (DA);

Environmental engineering;
RESUMO: Acredita-se perdurar nos ambientes formais e informais de ensino a crença de que as soluções para as mazelas da sociedade ocorram apenas pelo desenvolvimento científico, esquecendo-se das dimensões históricas e sociais envolvidas nesse contexto. Na tentativa de romper com esse modelo, iniciou-se a partir da década de 1970, propostas curriculares para a educação básica com destaque nas relações entre ciência-tecnologia-sociedade (CTS). O objetivo central desse movimento tem sido fomentar a alfabetização científica dos cidadãos, contribuindo para a construção da tomada decisões responsáveis sobre questões envolvendo CTS. Diante disso, esta pesquisa buscou identificar o alcance de ações CTS em um curso de Engenharia Ambiental no estado do Paraná. A coleta de dados se deu entre acadêmicos a partir do $7^{\circ}$ período, por meio de questionários semi-estruturados sobre temas que envolvam a produção de conhecimentos científico-tecnológicos e seu alcance para a sociedade e o ambiente. Para análises dos discursos foi utilizadas categorias da Análise do Discurso (AD). Tal metodologia permite uma reflexão voltada para a observação das manifestações discursivas explícitas e implícitas nos discursos. Um sucinto movimento analítico esclareceu a pertinência de discussões sobre ensino, epistemologia e apelo social envolvido nas pesquisas voltadas às engenharias ambientais no contexto contemporâneo.

ABSTRACT: It is believed to persist in formal and informal educational environments the belief that solutions to the ills of society occur only through scientific development, forgetting the historical and social dimensions involved in this context. In an attempt to break with this model, starting in the 1970s, curricular proposals for basic education, with emphasis on the relations between science-technology-society (STS). The central objective of this movement has been to promote the scientific literacy of citizens, contributing to the construction of making responsible decisions on issues involving STS. In view of this, this research sought to identify the scope of STS actions in an Environmental Engineering course in the state of Paraná. Data collection took place among academics from the 7th period, through semi-structured questionnaires on topics involving the production of scientific-technological knowledge and its reach to 
Ensino, Saúde e Ambiente - V12 (2), pp. 121-139, Ago. 2019

society and the environment. Discourse Analysis (DA) categories were used for discourse analyzes. Such methodology allows a reflection focused on the observation of explicit and implicit discursive manifestations in discourses. A succinct analytical movement clarified the pertinence of discussions about teaching, epistemology and social appeal involved in researches related to environmental engineering in the contemporary context.

\section{INTRODUÇÃO}

A ciência ao longo de sua história trilhou várias construções de conhecimentos, muitos dos quais adentraram o século XXI com vigor e possibilidade de uso. Possivelmente, o uso de métodos ricos em rigores e aspectos racionais tenha contribuído para o sucesso desse percurso. Tais características metodológicas presentes no formato das pesquisas científicas têm suas bases na Revolução Científica ocorrida entre os séculos XVI e XVIII (ZAMBIASI, 2006; HENRY, 1998).

Esse modelo de produção científica tem sido denominado por alguns estudiosos (LYOTARD, 2006; BEHRENS, 2003) de Ciência Moderna, representado pela valorização das especializações como forma de contribuir para a produção de conhecimentos mais precisos e eficazes, em detrimento de um modelo mais holístico, muitas vezes interpretado como algo superficial e abrangente.

Esse modelo de produção de conhecimento passou de apenas um escopo pragmático, no sentido de prático, para alcançar um forte discurso de ordem epistemológica e capaz de validar conhecimento por meio de tais perspectivas modernas. Acredita-se que tais valores discursivos tenham alcançado não apenas a divulgação científica dos periódicos, mas também o ensino e âmbito acadêmico durante a recontextualização escolar.

A partir da década de 1960 surgiram grupos, em princípio das ciências sociais voltados a analisar com cuidado o cenário científico e suas produções, de modo a enxergar os aspectos sociais envolvidos e seus níveis de participação na pesquisa. Isso, por conseguinte, traria movimentos preocupados com a ruptura de um formato de ciência neutro e linear.

Em contrapartida, na década anterior, em 1950, havia ocorrido o lançamento do primeiro satélite artificial - o Sputinik pelos Estados Unidos. Esse acontecimento propiciou no país, e em países concorrentes, o início de uma busca acelerada na formação de cientistas. Do ponto de visto do ensino, houve entre as consequências a construção de projetos curriculares com ênfase no método científico, tendo em vista desenvolver nos jovens o espírito científico. Com isso, houve propostas pedagógicas análogas ao chão de fábrica e ao viés apenas mercadológico (KRASILCHIK, 1987).

No final da década seguinte, educadores científicos começaram a se preocupar com o agravamento de problemas ambientais, questionando assim, uma educação científica que 
levasse em conta os aspectos sociais relacionados ao modelo de desenvolvimento tecnológico. Contudo, ainda pareceu persistir a presença de um modelo cientificista - crença na ciência como última instância validadora de conhecimentos - em vários âmbitos das pesquisas, principalmente, no que tange as áreas da engenharia, voltadas às aplicações científicas e matemáticas.

Autores como Auler e Delizoicov (2001) alertam sobre o fato de que essa perspectiva cientificista tenha contribuído para a persistência e fortalecimento de uma visão salvacionista em relação a ciência, corroborada pela crença de que ciência e tecnologia sejam produções neutras, e logo, desenvolvidas apenas para resolver problemas da humanidade. Desse modo, existe ainda na sociedade a crença de que as soluções de seus problemas e das mazelas sociais venham somente do desenvolvimento científico, esquecendo-se das dimensões histórico e sociais envolvidas nesse contexto.

$\mathrm{Na}$ tentativa de romper com esse modelo, iniciaram-se em vários países, no fim da década de 1970 e no começo da década seguinte, propostas curriculares para a educação básica com destaque nas inter-relações ciência-tecnologia-sociedade (CTS) (WAKS, 1990). No Brasil, a preocupação com a necessidade de formar cidadãos críticos, interatuando com a educação científica, se deu a partir dos anos de 1970, momento em que se iniciou de fato a pesquisa na área de educação em ciências no Brasil.

Na concepção de autores como Roberts (1991), o currículo de ciência com destaque em CTS são aqueles que tratam das inter-relações entre explicação científica, planejamento tecnológico, solução de problemas e tomada de decisão, sobre temas práticos de importância social. Dessa forma o planejamento de CTS pode ser interpretado como uma relação entre educação científica, tecnológica e social, onde são estudados simultaneamente com a discussão de seus aspectos históricos, políticos, éticos e socioeconômicos.

Entretanto, estudos na área de ensino de ciências, voltados às disciplinas de base conceitual como química, física e biologia - desvelaram existir ainda, nesses contextos, fortes aspectos desse modelo de ciência, representados por um cientificismo (CACHAPUZ et al, 2005).

Possivelmente, entre os motivos para isso, esteja o fato de que os professores de ciências ainda aparentam compreender que essa educação se limita ao conhecimento de teorias de funcionamento de determinados valores tecnológicos. O pouco que se tem alcançado em sala de aula é expor aos alunos como o conhecimento científico está vigente em diferentes recursos tecnológicos de seu cotidiano. Isso está muito distante do que se tem debatido sobre educação tecnológica em um planejamento de ciências com ênfase em CTS. 
Ensino, Saúde e Ambiente - V12 (2), pp. 121-139, Ago. 2019

É importante ressaltar que a intenção de trabalho do movimento CTS não se trata de um método de ensino ou teoria de aprendizagem, e sim de um conjunto de pensamentos de uma forma de olhar o mundo e se relacionar, na proporção de pensamentos quanto a um aspecto de construção de conceitos e de cidadania aprimorado ao ambiente de aprendizagem.

Autores como Cachapuz e seus colaboradores (2005) apontam haver pelo menos visões deformadas presentes no ensino. Acredita-se que isso contribua como resistência para que aspectos da visão CTS se estabeleçam como fomentador do processo de popularização da ciência, e logo de ações voltadas à alfabetização científica. A perspectiva ideológica de trabalho do movimento CTS está na contramão da ideia de ciência neutra, linear e fragmentada. Contudo, parece ainda haver resistências no contexto acadêmico, não no âmbito discursivo, mas sim no que tange a prática educacional.

Defende-se aqui que, quando essa perspectiva ideológica científica outorgada pela perspectiva de trabalho CTS se traduz em uma abordagem metodológica em sala, esse movimento de ruptura ocorre, havendo um deslocamento acadêmico de uma visão fragmentada de ciência rumo a uma noção reflexiva e interligada.

A partir dessas discussões e do seu alcance nos mais variados ambientes de trabalho surge essa pesquisa. Acredita-se que a necessidade de um currículo interligado entre ciência, tecnologia e sociedade não seja apenas algo para a agenda de cursos científicos de licenciatura, mas dos mais diversos perfis de profissionais. Para tanto, entende-se como algo legítimo e importante, identificar e refletir sobre, quais valores sobre ciência tem transitado em cursos bacharéis que tenham forte apelo científico e tecnológico. E assim, busca-se com essa pesquisa identificar o quanto o enfoque CTS tem alcançado a formação dos acadêmicos no curso de Engenharia Ambiental.

O enfoque CTS está atrelado ao estudo das relações presentes entre ciência, tecnologia e sociedade mediante uma análise crítica e interdisciplinar da ciência e da tecnologia no contexto social, tendo como intenção compreender os aspectos gerais do fenômeno científicotecnológico. Sendo assim, entre os motivos para a realização dessa análise no curso específico de Engenharia Ambiental, destaca-se a presença do caráter de aplicabilidade do curso, bem como, ter como nicho de trabalho o ambiente com finalidade de formar técnicos e pesquisadores. Ora, um dos recursos que deve ser desenvolvido pelo engenheiro ambiental é a análise da duração, magnitude e reversibilidade das transformações causadas pela atividade humana no meio ambiente, seja ela benéfica ou não.

A formação de engenheiros sempre submete a ligação entre as diferentes ciências aplicadas a construção de tecnologias e às inovações tecnológicas, constituindo o perfil de engenheiro demandado pela sociedade. O sinal desta relação é de que o engenheiro seja um 
profissional que desenvolve sua atividade na área de tecnologia; isso, com o compromisso de produzir tecnologia e trabalhar o desenvolvimento gerando bens para a sociedade, seguindo da produção científica disponível.

Concorda-se com Menestrina e Bazzo $(2008$, p.4) de que "a formação cidadã referese à inclusão dos acadêmicos nas problemáticas das comunidades e o estabelecimento por ele e por todos envolvidos no processo de aprendizagem de pontes entre os conteúdos ministrados na sua graduação e as relações que pode constituir entre a sua profissionalização e a sociedade.”

Diante disso, busca-se por meio desta pesquisa identificar possíveis valores científicos presentes no discurso acadêmico dos acadêmicos de graduação em engenharia ambiental da Universidade Tecnológica Federal do Paraná - UTFPR. E com isso, compreender qual o nível de alcance de um olhar CTS na formação desses acadêmicos.

\section{PROCEDIMENTOS METODOLÓGICOS E COLETA DE DADOS}

Esta pesquisa buscou detectar os valores implícitos nos discursos durante a formação acadêmica de engenheiros ambientais. Para tanto, foram coletados dados por meio de questionários semi-estruturados. O assunto presente no escopo das questões pairaram sobre ciência, tecnologia, sociedade e suas possíveis relações aos aspectos ambientais.

Nessa coleta de dados participaram doze acadêmicos do sétimo período do curso de Engenharia Ambiental de uma instituição pública da região Sul do país. A opção por acadêmicos desse período justifica-se devido ao fato de estarem na segunda metade dessa graduação. Portanto, acredita-se, terem presentes em seus discursos mais elementos que indicam a identidade e visão discursiva do curso de graduação.

Cabe destacar que todos os participantes foram conscientizados de que estavam participando de uma pesquisa, a qual foi gravada e transcrita. Para tanto, foi coletado o termo de consentimento de todos os envolvidos na pesquisa, sendo preservadas suas identidades. Deste modo, ao longo das análises, a identificação dos discursos se dará utilizando a letra inicial do primeiro nome do acadêmico, e havendo mais de um acadêmico com o mesmo nome, optouse em utilizar numeração na sequência [ex. A1, A2]. E isso de modo, a facilitar a organização dos discursos e preservar o anonimato dos participantes da pesquisa.

A coleta foi realizada no ano de 2015, sendo que o roteiro de questões semiestruturadas teve a intenção de permitir maior flexibilização discursiva. As questões aplicadas aos acadêmicos foram:

1) Atualmente muitas pesquisas têm surgido relacionando ciência e tecnologia. $\mathrm{Na}$ área de engenharia, quais você poderia destacar? 
Ensino, Saúde e Ambiente - V12 (2), pp. 121-139, Ago. 2019

2) Quais problemas você acredita existir durante a produção de avanços nas pesquisas na área de engenharia? Por quê?

3) Para você quais aspectos são mais relevantes na produção de conhecimento científico interferindo em sua "neutralidade"? Exemplifique Explique usando algum argumento derivado da pesquisa ou da investigação científica.

4) Qual a relação que você acredita existir entre ciência, tecnologia e sociedade nas produções da engenharia?

5) Pesquisas importantes têm surgido envolvendo biotecnologias e a diminuição de impactos na sociedade, como por exemplo, o equacionamento dos impactos ambientais. Para você, tais pesquisas têm alcançado a sociedade? Como? E se não, por que isso tem ocorrido?

Tais questões trazem à baila discussões sobre a concepção ampla de ciência. E, na sequência, suas relações com a sociedade e possíveis tecnologias que podem ser utilizadas. A intenção é de observar qual concepção de ciência paira sobre a formação do engenheiro ambiental, e logo, tal alcance na aplicação cotidiana do espectro ambiental.

Pesquisas realizadas nas áreas de ensino de ciências, envolvendo disciplinas como química, física e biologia, bem como em cursos de bases no ensino e licenciatura, revelam a existência de valores ideológicos de fragmentação na produção científica - muitas vezes nominados de valores típicos da modernidade, e ou, da ciência moderna. E isso, tanto do ponto de vista epistemológico quanto de recontextualização escolar e de divulgação midiática (RAMOS et al 2012; RAMOS, 2014).

Diante disso tais questões foram elaboradas na tentativa de identificar o quanto a presença da perspectiva de ciência consolidada na modernidade (ZAMBIASI, 2006) tem se estabelecido e sustentado em cursos de aplicação científica como, nesse caso, a engenharia ambiental. E ainda, compreender quais relações os acadêmicos - como aqui, os participantes dessa pesquisa -, tem estabelecido entre tais aspectos epistemológicos conceituais de ciência em suas perspectivas de aplicação social e retorno para a sociedade. Ora, trata-se de observar as possíveis relações presentes entre ciência, tecnologia e sociedade na formação do engenheiro ambiental. E logo, a implicação disso no perfil de formação dos engenheiros ambientais.

Como suporte metodológico para as análises, foi escolhido a Análise do Discurso, uma vez que, tal metodologia permite uma reflexão de espectro qualitativo, voltado para a observação das manifestações discursivas implícitas e não apenas explicitas dos discursos. Para tanto, utilizou-se como metodologia de análise dos discursos a Análise de Discurso (AD) na perspectiva francesa, a qual oportunizou o acesso aos sentidos estabelecidos nas produções verbais dos entrevistados. $\mathrm{Na} \mathrm{AD}$, a linguagem não é transparente, mas opaca, por isso, a $\mathrm{AD}$ se coloca diante da opacidade da linguagem. $\mathrm{O}$ analista ao utilizar a análise de discurso realiza 
uma leitura do texto enfocando a posição discursiva do sujeito, legitimada socialmente pela união do social, da história e da ideologia, produzindo sentidos. Na utilização da AD "o que é visado no texto é justamente uma série de significações que o codificador detecta por meio dos indicadores que lhe estão ligados" (PÊCHEUX, 1993, p. 65).

Diante do exposto, vale retratar que, essa pesquisa busca uma forma de análise que se proponha a compreender não apenas o conteúdo textual, mas também o sentido opaco no discurso. Deste modo, vê-se na AD um suporte metodológico significativo na perspectiva de perscrutar o discurso em seu sentido explicito e implícito, desvelando os valores conceituais de ciência que possivelmente justifiquem a visão dos acadêmicos participantes dessa pesquisa.

\section{ANÁLISE E DISCUSSÃo}

A AD se propõe a analisar, entre vários aspectos, da produção verbal e se constitui como uma opção quando há o interesse em um trabalho com o significante [linguística] para se alcançar os mecanismos de produção de sentido utilizados pelos sujeitos ao longo da produção do discurso. Considerando-se que tais mecanismos estejam ligados tanto ao sujeito quanto à sociedade que os determina em escalas variadas. Para tanto, a $\mathrm{AD}$ não se limita a analisar o corpus em si, mas em inseri-lo no contexto vivido, considerando o aspecto histórico e social de quem enuncia (ORLANDI, 2001).

Cabe destacar que, autores da AD mencionam a importância de se estruturar um percurso metodológico que permita a utilização deste referencial, embora ressaltem a necessidade de que essa trajetória precisa se adaptar aos questionamentos que mobilizam o pesquisador e as características do corpus a ser analisado (PÊCHEUX, 2002; ORLANDI, 2002). Diante disso, define-se como arcabouço metodológico para essa pesquisa a AD a partir das contribuições francesas perpassado por Eni Orlandi (2001).

De acordo com os passos propostos por Orlandi $(2001$; 2002) considera-se três etapas (e suas correlações) destacadas por essa autora como fundamental para esse percurso: $1^{\mathrm{a}}$ etapa passagem da superfície linguística [texto/discurso]; $2^{\mathrm{a}}$ etapa passagem do objeto discursivo [formações discursivas]; e a $3^{\mathrm{a}}$ etapa passagem do processo discursivo [formação ideológica e imaginária]. Diante disso, para construir as análises e discussões que seguem buscou-se perpassar tais momentos propostos pela perspectiva da AD.

$\mathrm{Na}$ construção das formações discursivas buscou-se desvelar os sentidos presentes nos discursos e suas possíveis acomodações em categorias discursivas que foram sendo geradas conforme à análise foi se estabelecendo. Esse processo somente ocorre após a transcrição de todos os discursos, de modo que antes mesmo de fazer uma análise pontual (questão a questão) 
Ensino, Saúde e Ambiente - V12 (2), pp. 121-139, Ago. 2019

é possível realizar uma identificação panorâmica. Para tanto, após uma dessuperficialização sobre os discursos de modo amplo, iniciou-se a construção das formações discursivas baseadas nos aspectos de interesse para a análise dessa pesquisa. Nessa perspectiva, optou-se em analisar e realizar a acomodação dos discursos em categorias após cada questão.

Ao longo desse processo foram surgindo categorias primárias que funcionaram como um primeiro filtro analítico relacionado à concepção ampla de ciência presente nos discursos, e na sequência um segundo filtro, ou seja, um desdobramento desse juízo de valor de ciência ampla aplicada as possíveis relações entre ciência, tecnologia e sociedade identificadas entre os discursos dos participantes, originando as categorias secundárias.

Para tanto, os discursos foram acomodados em quatro grandes categorias primárias e suas respectivas categorias secundárias, as quais seguem: 1) CIÊNCIA CAUSAL INTERNALISTA: - ciência reducionista; 2) CIÊNCIA NEUTRA E LINEAR: - participação social assimétrica; e/ou - relação CTS fragmentada; 3) CIÊNCIA NEUTRA E DE CREDIBILIDADE: - visão unilateral CTS; e 4) CIÊNCIA NÃO NEUTRA E DE CREDIBILIDADE ACRÍTICA: - visão dialógica CTS.

O conceito expresso em cada enquadramento categórico, ou seja, a explicação do significado de tais categorias foi sendo descrito a cada primeira aparição de enquadramento categórico discursivo. Seguem na sequência as formações discursivas e suas discussões [formação ideológica e imaginária] após cada questão em foco de análise. Optou-se por estabelecer uma subseção para a análise e discussão de cada uma das cinco questões. Para tanto, colocando como título destas a temática que envolveu a questão e os discursos, conforme o quanto segue.

Pesquisas relacionando ciência e tecnologia na área de engenharia - análise e discussão

Iniciando a coleta de dados os acadêmicos foram interpelados sobre quais pesquisas atuais nas engenharias consideravam relacionar ciência e tecnologia, podendo ter alcance social. Isso de modo a identificar se haveria o estabelecimento de relações entre aspectos da CTS como ciência e tecnologia nas produções de conhecimentos das engenharias. E surgiram discursos como:

\footnotetext{
Drones (vulgos robôs voadores) utilizados para pesquisa em campo, tanto para geo-referenciar algo até mesmo para uso monitoramento de espécie. O estudo de materiais mais resistentes e menos prejudiciais ao meio ambiente para revestimento em aterros sanitários e os aparelhos para captação de energia através de mares/oceanos (ACADÊMICO M1).

$\mathrm{Na}$ área de tratamento de esgoto há equipamentos com tecnologia de ponta para não ter contaminação no rio, porém esse tratamento só pode ser realizado com ajuda da ciência biológica e química que proporcionam estudos para realização das análises. Para o tratamento de emissões atmosféricas poluidoras têm equipamentos com tecnologia de ponta, mas a ciência que provou que alguns tipos de gás fazem mal para saúde e afins (ACADÊMICO A2).
} 
$\mathrm{Na}$ área de engenharia ambiental se destacam as relações e eco-toxicologia onde é preciso tanto da ciência, como também de equipamentos tecnológicos para realizá-los. Outro exemplo seria o uso de geotecnologias para determinar áreas e estudá-las aliando a ciência e a tecnologia. [...] Praticamente em tudo a ciência e a tecnologia seguem ligadas (ACADÊMICO F2).

Nesses três discursos a relação entre ciência e tecnologia aparece mais delineada. Observam-se dois movimentos distintos. Do ponto de vista da concepção de ciência ampla, permanece uma ideia de ciência neutra e causal, havendo apenas maior detalhamento sobre o quanto ciência e tecnologia caminham juntas. A noção de que ciência e tecnologia caminham juntas é importante, pois se trata de uma etapa importante para se alcançar a visão sistêmica de que ciência não é uma forma de produzir conhecimento isolado. Contudo, é preciso o rompimento da ideia de ciência ingênua e neutra para que se alcance também um olhar crítico e interligado entre ciência e os mais variados ingredientes sociais envolvidos e não apenas coadjuvantes nesse processo.

Pode ser identificado do ponto de vista positivo nesses três discursos a presença marcante de ciência interligada a tecnologia de modo bem consciente. Porém em frases como "a ciência provou (ACADÊMICO A2)" e ainda, "praticamente em tudo a ciência e tecnologia seguem ligadas" (ACADÊMICO F2) existe um eco discursivo que remonta a noção de infalibilidade científica, e aqui o termo infabilidade tem caráter provocativo do deslocamento do poder religioso para a ciência positivista (RÉGIS DE MORAES, 1983). Ora, parece haver a presença da concepção de ciência legitimadora de verdades, o que contribui para fortalecer a imagem de ciência neutra e linear, pois a verdade sai da perspectiva da relatividade para alcançar uma noção estanque. Para tanto, os três discursos parecem acomodar-se na categoria primária: CIÊNCIA NEUTRA E LINEAR e apontam para a categoria secundária a partir desse discurso, aqui produzida e nominada de categoria secundária relação CTS fragmentada.

Na tentativa de identificar se destacariam a presença de aspectos sociais nas pesquisas, e ainda como estabeleceriam relações entre tais aspectos e a produção científica, os acadêmicos foram questionados sobre: quais problemas que apontariam existir durante a produção de avanços nas pesquisas na área de engenharia.

Grande parte dos acadêmicos mencionou o dinheiro e logo, a falta de incentivo, como fator importante para as pesquisas. Entre tais discursos destacam-se:

Falta de incentivo público, privado, a falta de preocupação com o meio ambiente, custos. Muitas das tecnologias são caras para implantação, se o governo incentivasse e divulgasse mais e os custos fossem menores, mais pessoas teriam capacidade de aderir a eles (ACADÊMICO A1).

Falta de recurso econômico para o investimento nessas novas tecnologias. O Brasil é um país rico em energias renováveis, porém devido aos custos dos equipamentos, aos impostos, e à falta de investimento, acaba-se optando pela energia mais barata, porém uma das mais prejudiciais ao meio ambiente e à biodiversidade que é a energia a partir de hidrelétricas (ACADÊMICO F1). 
Verba para custear e incentivar a pesquisa, tempo necessário para realização e planejamento adequado (ACADÊMICO J).

Dinheiro e conflitos de interesses como o engenheiro é o profissional ligado a resolução de problemas específicos de sua área, na maioria das vezes o conhecimento é barrado pela falta de interesse de quem tem o dinheiro. [...] (ACADÊMICO P).

Tais discursos apontam para a categoria primária CIÊNCIA NEUTRA E LINEAR, a qual já foi exemplificada e mencionada na análise da primeira questão. Contudo, se estabelece nesse discurso a categoria secundária participação social assimétrica. O conceito de assimetria aqui atrela-se ao discurso que considera haver atores sociais, ou seja, a presença de aspectos na produção científica além do conhecimento em produção, como: política, poder e status de pesquisadores, religião, sociedade. Entretanto, distribuem em seus discursos sempre papéis negativos a esses aspectos. O que por sua vez, traz a sensação de que qualquer coisa que perpasse a produção científica tente tirar sua neutralidade inerente, revelando-se como um "mal necessário", ou seja, algo ruim que atrapalhe a ciência.

Houve ainda, discursos que trouxeram aspectos importantes para a discussão. Entre tais, aspectos como: jogo de interesses de empresas, deficiências e necessidades tecnológicas, erros nas coletas de dados e a falta de conhecimento da população.

Um fator relevante que atrapalha avanços relacionados ao tratamento de efluentes, muitas vezes é o descaso de empresas, as quais deveriam incentivar tais avanços (ACADÊMICO M2).

Além do fato de que a preocupação ambiental é tão recente quanto às tecnologias industriais, fazendo com que as tecnologias dessa área não sejam tão avançadas, [...]. (ACADÊMICO L).

Pelo menos aqui na Universidade, um problema que dificulta o avanço é a falta de interação entre a universidade e as empresas da região. Talvez, se houvesse essa relação poderiam ser desenvolvidas pesquisas científicas e tecnológicas com maior relevância nas áreas que a engenharia ambiental atua, fazendo com que os avanços na área que fossem mais significativos. [...]. (ACADÊMICO G).

Coleta de dados errados que pode ocasionar erros. [...] Falta de manutenção de equipamentos, custos, política. Porque todos estes fatores influenciam no desenvolvimento de pesquisas e avanços da ciência (ACADÊMICO F2).

O interesse político é um grande fator de "travamento" já que é necessário aprovação e incentivos financeiros. A falta de interesses da massa sobre assuntos relevantes e seus avanços, entender que a produção de um combustível que não seja de matéria prima fóssil é muito mais importante que o lançamento de IPhone 6. [...] (ACADÊMICO R).

Esses discursos se enquadram na categoria primária e secundária anterior, porém apresentam outros ingredientes importantes, como o fato de manterem a produção científica em um status cristalizado de validação de verdades, ao passo que os outros aspectos à volta que complicariam esse processo. Isso por sua vez, demonstra a importância do processo de alfabetização científica alcançar a formação profissional e se desdobrar em ações de políticas de governo que alcancem os diversos grupos leigos sociais. Isso tende a minimizar processos 
Ensino, Saúde e Ambiente - V12 (2), pp. 121-139, Ago. 2019

fragmentários oriundos da visão moderna de ciência, contribuindo a cidadania engajada na participação de informes públicos para tomadas de decisão.

Os acadêmicos foram novamente questionados sobre possíveis interferências durante o processo de construção científica. Na questão anterior os acadêmicos apontaram para aspectos externos como empecilhos e consideraram' a produção do conhecimento e seu arcabouço como isentos. Para tanto, foram questionados a responderem quais aspectos mais participam da produção de conhecimento científico interferindo em sua neutralidade, exemplificando isso.

A intenção era identificar se perante a uma pergunta mais objetiva, esse movimento discursivo se manteria, e ainda o quanto haveria argumentos de sustentação ao longo da exemplificação de uma situação ou conhecimento produzido. Surgiram discursos como:

Região, costumes crenças. Como no estudo das células tronco, teve um caso em que um homem, não me lembro bem, mas se não me engano era pastor, lutava contra o andamento das pesquisas alegando que estavam tirando vidas até que seu filho precisou (ACADÊMICO A1).

[....]. [....],vejo falta de incentivo do próprio governo para pesquisas de faculdade (ACADÊMICO A2).

Política e religião. Exemplo de pesquisa: teoria evolutiva, teoria criacionista (ACADÊMICO F1).

Aspectos políticos, sociais e financeiros. Porque todo projeto tem um custo, e geralmente este projeto tem um custo, e geralmente este acaba afetando a sociedade de forma direta e indireta, pois a produção de conhecimento não acaba sendo feita a toa, e também depende da política em relação às leis, pois não se pode ir fazendo qualquer coisa sem antes consultar leis ou parâmetros estabelecidos por ela. Por exemplo, a arborização urbana, envolve um processo de estudo ambiental relacionado às plantas que você tem em determinado local, e como ela interfere nas outras plantas, a interferência e relação ao homem, seja benefícios como sombra, meio social se for em praças, e também malefícios como acessibilidade pelas calçadas, já que a planta pode rompê-la por causa do crescimento da raiz, a fiação elétrica, plantas invasoras que se reproduzem rápido e tomam conta do ambiente, e isso tudo pode ser relacionado com a lei de arborização, acessibilidade, redes elétricas, corte e poda da árvore ( ACADÊMICO F2).

Por se tratar da área de engenharia ambiental, acredito que a dificuldade de acesso a dados relacionados ao meio ambiente, já que muito ainda se encontra em irregularidade. Um exemplo é a dificuldade, que muitos professores relatam, de ir a campo em de terminados lugares, porque muitos dos que os administram temem que a visita tenha caráter fiscalizador. [...] (ACADÊMICO G).

Interesses econômicos, políticos, sociais e religiosos. Duas situações podem ser exemplificadas a do geocentrismo que batia de frente com a igreja católica, esta que foi responsável pelo atraso da ciência durante muito tempo, [...] (ACADÊMICO J).

Os investimentos. Por exemplo, alguma pesquisa que esteja desenvolvendo a resolução de algum problema lucrativo para o investidor, pode sofrer pressão no sentido de cortes de investimento para que não seja dada sua continuidade (ACADÊMICO L).

Novamente a questão religiosa e dementes conservadores; acho que o exemplo seria do uso de células troncos para ajudar na cura de algumas doenças (ACADÊMICO M1).

Os aspectos com maior significância é a elaboração de um estudo, colocá-lo em prática, pois só assim saberia se realmente pode ser implantado ou não, com 100\% de precisão (ACADÊMICO M3).

O desenvolvimento cultivo e o pensamento científico, justamente com a criação das hipóteses e o entendimento (ACADÊMICO P). 
Ensino, Saúde e Ambiente - V12 (2), pp. 121-139, Ago. 2019

As pessoas são bombardeadas com informações por todos os lados, não conseguem manter um fluxo ideológico sério de cunho científico. Hoje em dia as pessoas são como patos, não voam nem nadam direito, sabem um pouco de tudo, mas nada em específico, manter a ideia de que: "sempre tem alguém fazendo isso por mim" não ajuda e até atrapalha, informação é poder e não apenas para manter uma "conversa cabeça" na mesa de bar. [...]. (ACADÊMICO R).

Observou-se pouca distinção dos argumentos ainda presentes na questão anterior, de modo que, mesmo uma questão mais direta e a necessidade de apontar uma ilustração da situação não foram suficientes para deslocar o acadêmico de sua posição inicial em relação à visão epistemológica que ainda defende sobre ciência - uma visão reducionista e determinista. Isso está atrelado à idéia categórica de CIÊNCIA CAUSAL INTERNALISTA. Nessa concepção se estabelece a noção de neutralidade na produção científica como única validadora de verdades. Ora, sempre os outros aspectos aparecem como: coadjuvantes, sempre como problemas, etc. Isso demonstra uma fragilidade conceitual sobre a concepção de ciência, pois instiga para o fato de que, a percepção de falhas no processo de construção científica -, o que é natural, pois se trata de um processo social -, seria suficiente para abalar sua credibilidade.

Para tanto, na sequência os acadêmicos foram questionados a mencionarem se existia e quais seriam as possíveis relações existentes entre ciência, tecnologia e sociedade nas produções de engenharia. Destacam-se dois grandes grupos discursivos.

Os estudos que ciência, tecnologia e sociedade são direcionados para melhoria na qualidade de vida, saúde, do meio em que vivemos ( ACADÊMICO A1].

A tecnologia existe por causa da ciência e dos diversos estudos que está propôs. E dessa forma a sociedade observe que a ciência e a tecnologia têm a oferecer, porém muitas vezes essa sociedade se apega mais a tecnologias do que para a ciência. Por exemplo, se paga a celulares novos do que para o tratamento de uma doença que a ciência está estudando (ACADÊMICO A2).

Estão relacionados, já que, a ciência, entre outros objetivos, busca a tecnologia para solucionar problemas (produções de engenharia) voltados para a sociedade (ACADÊMICO F1).

É uma relação essencial e conturbada pois a ciência estuda e promove os conhecimentos convicções, a tecnologia aplica a ciência para a utilização da sociedade aos seus interesses muitas vezes de maneira nociva ligado principalmente

a questões econômicas e benéficas (ACADÊMICO J).

A ciência utiliza-se da tecnologia para colocar em prática seus avanços a fim de atender e chegar à sociedade (ACADÊMICO L).

Uma dá base para outra; por exemplo: com a ciência ganhamos o conhecimento e aptidão para aplicar em alguma tecnologia, que irá ser um facilitador para a execução, que será fornecida para a sociedade (ACADÊMICO M1).

Ciência e tecnologia é uma parceria onde quem ganha é a sociedade, pois ambos trabalhando junto podemos ter dados mais precisos e resultados de melhor entendimento. [...]. (ACADÊMICO M3).

Uma é diretamente relacionada a outra pois é através do conhecimento científico e da tecnologia que a engenharia vai tentar atender as necessidades da sociedade (ACADÊMICO P).

Nesse primeiro grupo discursivo fica caracterizada a categoria primária de CIÊNCIA

NEUTRA E DE CREDIBILIDADE, pois a ciência aparece sempre relacionada de modo neutro 
e voltada para a produção de benefícios para a sociedade. Os ingredientes e atores sociais têm um viés não dialógico, sem a mesma importância da ciência, e muitas vezes ligada a um papel negativo, caracterizando-se o discurso na categoria secundária visão unilateral CTS, ou seja, não há uma relação igualitária nos papeis da ciência, tecnologia e sociedade.

Para tanto, não há espaços nesses discursos para a percepção de interesses dentro do próprio contexto da comunidade científica não neutros. Entretanto, surgiram discursos mais transitórios, os quais seguem:

[...] ambos estão ligados e andam em conjunto, pois obras ou projetos da engenharia interferem na sociedade em forma de qualidade ou malefício e as tecnologias utilizadas nesses projetos/obras (ACADÊMICO F2).

Acredito que um depende do outro. Ciência e tecnologia não se desenvolvem separadas e a sociedade é quem cria a demanda por inovações. Talvez, um não existisse sem o outro (ACADÊMICO G).

Acredito que o conceito de ciência abrange todos estes aspectos já que uma está intimamente ligada a outra. É necessário um problema social para que a tecnologia melhore as ações preventivas e mitigadoras que a ciência provavelmente já estuda. Não há como separar essas 3 unidades uma sem a outra não existiria, apesar dos apesares (ACADÊMICO R).

Nesses discursos, aparecem aspectos da categoria primária CIÊNCIA NÃO NEUTRA E DE CREDIBILIDADE ACRÍTICA. Essa categoria se estabelece em discursos em que ocorre a percepção de que a ciência seja passível de problemas e interferências, porém isso não necessariamente vem acompanhado no discurso da noção de possíveis posicionamentos ativos e intencionais por parte daqueles que fazem ciência, por exemplo. Parece existir mesmo que incipiente a quebra do modelo causal e linear rumo à noção de complexidade, esta atrelada a um conhecimento mais denso e conceitual em que se é capaz de identificar necessidade de rupturas conceituais epistemológicas para que determinados conhecimentos se sustentem. E nesse caso, estabelecida pela percepção de que a ciência faz parte do tripé sociedade tecnologia. Para tanto, inicia-se nesses discursos aspectos típicos da categoria secundária visão dialógica CTS, ou seja, a percepção de que existe uma relação recursiva entre ciência, sociedade e tecnologia. É preciso que esses conhecimentos e atores sociais "se conversem", pois estão intrinsecamente relacionados e se retroalimentam.

Ao final do processo discursivo foi comentado com os acadêmicos que grandes pesquisas têm surgido envolvendo biotecnologias e a diminuição de impactos na sociedade, como por exemplo, impactos ambientais. E foi perguntado a eles se acreditam que tais pesquisas têm alcançado a sociedade e de que modo.

Surgiram vários discursos que voltaram a apresentar o mesmo movimento das duas últimas questões analisadas, aqui de modo a não se estender muito, representadas pelos três discursos que seguem: 
Ensino, Saúde e Ambiente - V12 (2), pp. 121-139, Ago. 2019

Acho que somente o que tem valor político acaba chegando a sociedade. Muito tem a ver também com a demanda criada na sociedade por formas de melhorar o ambiente em que vivem. [...] (ACADÊMICO G).

De certa forma sim. Há muitas pessoas que ainda não tomaram consciência de que é preciso preservar e que é possível ajudar fazendo sua parte. [...]. (ACADÊMICO A1).

Em países mais avançados economicamente essas pesquisas alcançam mais a sociedade do que em países subdesenvolvidos. [...]. (ACADÊMICO F1).

Esses três discursos dos acadêmicos A1, G e F1 voltam a mencionar aspectos como política, economia e cultura como responsáveis pelo não alcance dos benefícios das produções científicas junto a sociedade. Até a população aparece como uma entidade culpada pela sua própria não consciência. Tais formações discursivas mantêm-se nas categorias: primária e secundária CIÊNCIA NEUTRA E DE CREDIBILIDADE: visão unilateral CTS.

Todavia, surgiram discursos transitórios, como o que segue:

Em relação às pesquisas envolvendo biotecnologias e a diminuição de impactos na sociedade como os impactos ambientais, creio que ainda têm-se muito a fazer. Há muitas pesquisas muito boas que não saem do papel, mas isso não se dá apenas por culpa do pesquisador, mas sim, a sociedade e também do governo. Para alcançar da sociedade visando melhorar a qualidade de vida delas, devese fazer uma aproximação maior entre a universidade e a população. [...]. (ACADÊMICO F2).

O acadêmico F2 apesar de deixar em última instância como culpado a sociedade, apontou a falha de muitas pesquisas não saírem do papel, e aparecer que o pesquisador é um ser ativo nesse processo e não apenas um maquinário da pesquisa, sem interesses e com papel ativo.

Outro discurso que aponta para a sociedade foi o do acadêmico J ao retratar que: "as pesquisas existem e algumas são promissoras e consistentes, mas alcançar a aplicação na sociedade é algo utópico e isso se deve a mudanças de mentalidade e comportamento, algo quase impossível em um lugar onde interesses econômicos e próprios são prioridades" [ACADÊMICO J]. Ora, surge nesse discurso à percepção da necessidade de mudança da mentalidade e do comportamento social. É muito importante que ocorra a percepção de um modelo de recontextualização de ensino de ciências fragmentado e não conectado. Ainda que o discurso não apontasse para essa necessidade de conexão entre ciência, tecnologia e sociedade já se deslocou da noção estanque de reprodução, pois o discurso mostra inquietação quanto ao engessamento de mentalidade.

Já o acadêmico L destacou a falta de conectividade entre conhecimento e sociedade, este devido à legislação e aspectos políticos, ao dizer que: "acredito que as biotecnologias não vêm alcançando diretamente a sociedade no sentido de reduzir impactos ambientais, já que elas são aplicadas normalmente somente na legislação que normalmente tem limites largos nessa questão". [ACADÊMICO L]. Mesmo que de modo ainda não simétrico, surge nesses discursos 
Ensino, Saúde e Ambiente - V12 (2), pp. 121-139, Ago. 2019

a presença de atores sociais de modo ativo e conectado, o que parece ser um aspecto positivo de acordo com a visão interativa CTS.

Encerrando esse movimento analítico surgiram formações discursivas como:

\begin{abstract}
Mais ou menos. Eu só cheguei a tomar conhecimento disso na faculdade. E na faculdade, acho que é mais para não alcançar do que alcançar. Eu, por exemplo, participo de projeto de extensão que envolveu retorno para a sociedade e existem mais projetos assim [...] e foram poucas vezes que vi a faculdade se envolver deste modo com a sociedade. Entretanto temos capacidade de aumentar mais este alcance, só falta mais investimento (ACADÊMICO M1).

Olhando para o cenário do Brasil, acredito que ainda falta muita interação entre a academia, o poder público e a população. $\mathrm{O}$ aluno, dentro da academia não entende como e porque ele deve dar retorno a sociedade, e a sociedade muitas vezes não vê a importância da academia e não sabe o que ela pode fazer por eles. O mesmo vale para o poder público que muitas vezes não dá importância necessária para a universidade para resolução dos problemas (ACADÊMICO P).
\end{abstract}

Essas duas formações discursivas do acadêmico M1 e P além de permanecerem no mesmo movimento dos discursos apresentados traz para a roda da interação a universidade. Isso é muito relevante, pois além da compreensão de que existam vários pilares importantes no processo de uma boa condução e alcance das produções científicas rumo à sociedade, ainda detectou o papel importante e muitas vezes deficiente da universidade.

Acredita-se que em várias situações as práticas dos projetos de extensão somente alcancem a sociedade quando o resultado é imediatista, ou seja, se o benefício é de longo prazo, ou ainda se a contrapartida social requerer perder recurso econômico o projeto fica ameaçado. Isso demonstra haver muitas falhas nesse trâmite. Certamente a mudança de mentalidade e de juízo de valor da sociedade precisa se reestruturar a partir da conscientização do real valor dos recursos naturais. Entretanto, acredita-se também ser necessário que as discussões sobre tais aspectos e a mudança de um modelo ainda utilitarista mercantil se desfaleça durante o processo de formação acadêmica do engenheiro ambiental.

\title{
CONSIDERAÇÕES
}

Esse breve movimento analítico desvela a pertinência de discussões sobre ensino, epistemologia e o apelo social envolvido nas pesquisas voltadas às engenharias ambientais em nosso contexto contemporâneo.

Ao longo das análises foi possível observar a noção sobre CTS ainda fragmentada, havendo o estabelecimento de relações entre ciência, tecnologia e sociedade de modo mecânico, sem uma distribuição de poder e valor equacional entre as três esferas, havendo apenas um repasse de benefícios científicos a partir do uso das tecnologias, as quais parecem funcionar apenas como suporte, e da sociedade como consumidora desse processo. Esse modelo mostrase unidirecional, tendo sido criticado na área de ensino de ciências, e isso por apenas reproduzir 
ciência entre as pessoas sem colocá-las no circuito dialógico importante para a construção da cidadania científica (LEWENSTEIN, 2003).

Foi possível identificar também em discursos presentes principalmente voltados às problemáticas durante a produção de avanços nas pesquisas na área de engenharia a presença de concepções de ciência neutra, desconsiderando-se a noção de produção social. Essa concepção tende-se a abalar diante de fissuras em grandes paradigmas científicos, de modo que o juízo de valor sobre a ciência fica enfraquecido e fragilizado, gerando um reducionismo envergonhado (LEITE, 2007) - crença de que a ciência seja a única responsável pela produção de conhecimento, reduzindo-se tudo a esse modelo de produção, e logo havendo um envergonhamento e frustração toda vez que um conhecimento é desconstruído para que outro o interponha. Ora, não se trata de fragilizar ou desconstruir a legitimação da ciência como forma de produção de conhecimento, mas de contribuir para o deslocamento de uma ideia frágil pautada numa crença ingênua, que não suporte qualquer frustração perante uma ruptura conceitual.

Acredita-se que alguns formatos de divulgação científica tenham contribuído para recontextualizar esse modelo unidirecional de ciência, no qual as pessoas entendam que precisem saber o mínimo e consumam o produto produzido pela ciência, sem maiores necessidades de compreensão daquele conhecimento. Entretanto, não se defende a ideia de que todas as pessoas saibam dissolver o que consta dentro da "caixa-preta" produzida pela ciência. Mas de incentivar no ambiente escolar desde as séries iniciais a partir de um currículo espiral (BRUNNER, 1960) alcançando as graduações, um modelo de discussão reflexiva sobre as produções de conhecimento. Pois é preciso obter um arcabouço mínimo de conhecimento de um processo para conseguir formar uma opinião precisa e ter uma visão imbricada da ciência, tecnologia e sociedade.

O que pode ser observado é que desde as séries inicias esse processo parece apenas se reproduzir. E isso de modo que, o cidadão vai conhecendo a conta-gotas um pouco mais pelo currículo engessado os conhecimentos mais sofisticados, porém se servindo deles apenas para reproduzi-los em seu caráter de aplicação como um conhecimento fragmentado e isolado.

Defende-se a ideia de tais aspectos, antes de um problema de ensino e aprendizagem desvele-se como um problema epistemológico que aqui nessa pesquisa relaciona-se à construção da ciência ao longo da história da humanidade. Tais indícios e discussões tem se dado no ensino de ciências. Contudo, a detecção de que isso alcance os cursos de aplicação como a engenharia ambiental corrobora para a ideia de que se mostram pertinentes análises e discussões, como essa que aqui se estabelece. E isso, como ponto inicial de deslocamento de uma visão unilateral de ciência rumo a uma perspectiva de ciência reflexiva, em que 
Ensino, Saúde e Ambiente - V12 (2), pp. 121-139, Ago. 2019

perspectivas aplicadas da ciência são conectadas aos diversos nichos sociais. Possivelmente, ações apresentadas pelas perspectivas do movimento CTS e do olhar voltado à alfabetização científica funcionem como suporte para isso.

Encerram-se essas considerações apontando que as análises até aqui confirmam as conjecturas iniciais dessa pesquisa de que, assim como no ensino de ciências, nas áreas aplicadas como a engenharia exista a necessidade de um currículo integrador nas áreas de ciências com destaque nas inter-relações entre a explanação científica, a organização tecnológica, solução de problemas e tomada de decisão, sobre temas práticos de importância social, ou seja, a aplicação da visão CTS nas produções de conhecimento aplicáveis das engenharias, como a engenharia ambiental.

Para tanto, defende-se que discussões que considerem os aspectos epistemológicos conceituais do produto científico e as possíveis relações desse conhecimento de modo conectado à tecnologia e sociedade se estabeleçam no cenário de formação acadêmica. Possivelmente, o enfoque voltado à perspectiva da alfabetização científica junto às sugestões de trabalho do movimento CTS contribuam para o desdobramento dessas ações em cursos de graduações como a engenharia ambiental dos cursos de formação inicial e nos documentos oficiais que regem a educação básica.

\section{AGRADECIMENTO}

Agradecemos à Fundação Araucária do Paraná que contribuiu para que esse trabalho fosse realizado por meio da contemplação de uma bolsa de iniciação científica para a bolsista Mariana Pereira de Souza com vigência de agosto de 2014 a julho de 2015.

\section{REFERÊNCIAS}

AULER, D.; DELIZOICOV, D. Alfabetização científico-tecnológica para quê? Ensaio - Pesquisa em Educação em Ciências, 3, 1, 105-115, 2001.

BEHRENS, M.A. O paradigma emergente e a prática pedagógica. Curitiba: Champagnat, 2003.

CACHAPUZ, A. A necessária renovação do ensino de ciências. 1. ed. São Paulo: Cortez, 2005.

CHASSOT, A. Alfabetização científica: uma possibilidade para a inclusão sócia. Revista Brasileira de Educação, 22, 89-100, 2003.

HORTA BARBOSA, L. H. História da Ciência. Rio de Janeiro: IBBD, 1963.

HENRY, J. A revolução científica e as origens da ciência moderna. Rio de Janeiro: Jorge Zahar, 1998. 
Ensino, Saúde e Ambiente - V12 (2), pp. 121-139, Ago. 2019

KRASILCHIK, M. O professor e o currículo das ciências. São Paulo: EPU; EDUSP, 1987.

LEWENSTEIN, B.V. Models of public communication of science \& technology.

Em:http://www.somedicyt.org.mx/assets/hemerobiblioteca/articulos/

Lewenstein_Models_of_communication.pdf

LYOTARD, J.F. A condição pós-moderna. Rio de Janeiro: José Olympio, 2006.

MENESTRINA, T.C.; BAZZO, W.A. Ciência, tecnologia e sociedade e formação do engenheiro: análise da legislação vigente. Revista Brasileira de Ensino de Ciência e Tecnologia, v.1, n. 2, mai/ago, 2008.

ORLANDI, E. P. Discurso e texto: formulações e circulação dos sentidos. Campinas (SP): Pontes, 2001.

ORLANDI, E. P. Análise de discurso: princípios e procedimentos. Campinas (SP): Pontes, 2002.

PÊCHEUX, M. Análise Automática do Discurso (AAD-69). Trad. E. P. Orlandi. In: GADET, F.; HAK, T. Por uma Análise Automática do Discurso: uma introdução à obra de M. Pêcheux. Campinas: Ed. da Unicamp, 1993, p. $61-105$.

PÊCHEUX, M. O Discurso: estrutura ou acontecimento. Campinas: Pontes, 2002.

RAMOS, F.P; NEVES, M.C.D.; CORAZZA, M.J. O conceito de gene: paradigmas ou incertezas para o século XXI? Maringá: Massoni, 2012.

RAMOS, F. P. Projeto Genoma Humano: aspectos epistemológicos e pragmáticos no discurso acadêmico. 2014. 135 p. Tese (Doutorado em Ensino de Ciências e Educação Matemática) - UEL Universidade Estadual de Londrina.

RÉGIS DE MORAIS, J.F. Ciência e tecnologia: introdução metodológica e crítica. Campinas: Papirus, 1983.

WAKS, L. J. Educación en ciencia, tecnología y sociedad: orígenes, desarrollos internacionales y desafíos actuales. In: M. MEDINA; J. SANMARTÍN (Orgs.). Ciencia, tecnología y sociedad: estudios interdisciplinares en la universidad, en la educación y en la gestión política y social. (pp. 42-75). Barcelona: Anthropos; Leioa (Vizcaya): Universidad del País Vasco, 1990.

ZAMBIASI, J.L. Do racional-positivismo ao construcionismo científico. In: P. M. MARINI. (Org.). Ensino de Ciências: Pesquisas e Reflexões. (pp. 68-83). Ribeirão Preto: Holos, 2006.

\section{SOBRE OS AUTORES}

\section{AUTOR 1.}

Licenciada em: Ciências, Biologia e Pedagogia. Doutorado em Ensino de Ciências e Educação Matemática pela UEL e Pós-doutorado em Educação para a Ciência e Matemática pela UEM. Professora Adjunta na UTFPR, campus de Campo Mourão. Atualmente leciona no curso de graduação em Engenharia Ambiental e no Programa do MPEF. Desenvolve pesquisas envolvendo: história e epistemologia da ciência, ensino-aprendizagem e popularização da ciência. 


\section{AUTOR 2.}

Graduado em Física; Doutor em Educação pela Unicamp. Especialista em Educação e Professor Titular da UEM atuando nos Programas de Pós-Graduação em Ensino de Ciências e Tecnologia (-UTFPR/PG) e de Educação para a Ciência e a Matemática da UEM. Tem experiência na área de Educação e Divulgação Científica, Alfabetização Científica, Linguagem Verbo-Visual aplicada à Divulgação da Ciência, História, com ênfase em HFC.

\section{AUTOR 3.}

Licenciado em Física; Doutorado em Educação Para a Ciência e o Ensino de Matemática pela Universidade Estadual de Maringá. Atualmente é professor adjunto na UTFPR atuando no Programa do MPEF, campus de Campo Mourão. Desenvolve pesquisas nos seguintes temas: ensino de ciências e astronomia, formação de professores e recursos metodológicos para o ensino de ciência e astronomia e história e epistemologia da ciência.

\section{AUTOR 4.}

Acadêmica do curso de Engenharia Ambiental pela UTFPR. Dirigente estadual do CREA Júnior/PR. Foi bolsista de pibic pela Fundação Araucária do Paraná, desenvolvendo pesquisas relacionadas a concepções de ciência e cts. Voluntária no projeto de extensão pela Fundação Araucária do Paraná, desenvolvendo pesquisas sobre dimensionamento, capitação e utilização de água de chuva no campus UTFPR - Campo Mourão. 